\title{
Salvia miltiorrhiza solution and its active compounds ameliorate human granulosa cell damage induced by $\mathrm{H}_{2} \mathrm{O}_{2}$
}

\author{
YING LIANG $^{1 *}$, LIYING KANG $^{2 *}$, ZIHE QI $^{2}$, XING GAO $^{1}$, HUILI QUAN ${ }^{3 *}$ and HUIFANG LIN ${ }^{3 *}$ \\ ${ }^{1}$ Reproductive Medicine Center and Prenatal Diagnosis Center, Shijiazhuang Obstetrics and \\ Gynecology Hospital, Shijiazhuang, Hebei 050011; ${ }^{2}$ Department of Science and Technology, \\ Hebei University of Chinese Medicine, Shijiazhuang, Hebei 050200; ${ }^{3}$ Department of Gynecology and \\ Obstetrics, Shijiazhuang Obstetrics and Gynecology Hospital, Shijiazhuang, Hebei 050011, P.R. China
}

Received May 7, 2019; Accepted January 3, 2020

DOI: $10.3892 / \mathrm{etm} .2020 .9496$

\begin{abstract}
The dried roots or rhizomes of Salvia miltiorrhiza Bge are commonly used in Chinese medicine to promote blood circulation and regulate menstruation. Salvianic acid A and salvianolic acid B are the main active water-soluble compounds in Salvia miltiorrhiza solution. The present study investigated the protective effect of Salvia miltiorrhiza solution and its active compounds in $\mathrm{H}_{2} \mathrm{O}_{2}$-induced cell damage of the human ovarian granulosa tumor cell line (KGN) in vitro, as well as its underlying mechanism. Cell viability was detected using a Cell Counting Kit- 8 assay. In addition, the levels of malondialdehyde (MDA), superoxide dismutase (SOD), glutathione (GSH) and tumor necrosis factor- $\alpha$ (TNF- $\alpha$ ) were measured. Western blotting was performed to detect the protein expression of cleaved caspase-3 and caspase-9. Furthermore, immunocytochemistry was used to detect the expression of TNF- $\alpha$. It was demonstrated that Salvia miltiorrhiza solution, salvianic acid A and salvianolic acid B did not affect the viability of KGN cells. Additionally, salvianic acid A and salvianolic acid B significantly reduced the $\mathrm{H}_{2} \mathrm{O}_{2}$-induced increased MDA levels, and reversed the $\mathrm{H}_{2} \mathrm{O}_{2}$-induced suppression of SOD and GSH activities in KGN cells $(\mathrm{P}<0.05)$. Treatment with Salvia miltiorrhiza solution, salvianic acid A and salvianolic acid B significantly reduced
\end{abstract}

Correspondence to: Dr Huifang Lin or Dr Huili Quan, Department of Gynecology and Obstetrics, Shijiazhuang Obstetrics and Gynecology Hospital, 206 East Zhongshan Road, Shijiazhuang, Hebei 050011, P.R. China

E-mail: huifanglin001@hotmail.com

E-mail: quanhuili1971@163.com

*Contributed equally

Abbreviations: KGN, human ovarian granulosa tumor cell line; SOD, superoxide dismutase; MDA, malondialdehyde; GSH, glutathione; TNF- $\alpha$, tumor necrosis factor- $\alpha$; GCs, granulosa cells

Key words: Salvia miltiorrhiza, salvianic acid A, salvianolic acid B, human ovarian granulosa tumor cells, oxidation the overexpression of cleaved caspase-3, cleaved caspase-9 and TNF- $\alpha$ compared with the $\mathrm{H}_{2} \mathrm{O}_{2}$-treated group $(\mathrm{P}<0.05)$. Therefore, the present results indicated that Salvia miltiorrhiza solution and its main water-soluble compounds, salvianic acid $\mathrm{A}$ and salvianolic acid $\mathrm{B}$, ameliorated $\mathrm{KGN}$ cell damage induced by $\mathrm{H}_{2} \mathrm{O}_{2}$.

\section{Introduction}

Assisted reproductive technology has been widely used to treat patients with infertility complications $(1,2)$. Clinical ovulation induction, ovulation collection and transplantation techniques for assisted reproduction have been optimized, which has improved pregnancy rates and successful deliveries (3). However, negative outcomes associated with assisted reproductive technology are associated with the effects of certain primary diseases, including severe endometriosis, polycystic ovary syndrome and old-age, which lead to a significant decline in the quality of eggs and embryos, and the clinical pregnancy rate (4). Oxidative stress damage in the follicular microenvironment contributes to the decline of oocyte quality in these primary diseases (5). Various gynecological diseases, such as endometriosis, polycystic ovary syndrome and reproductive aging, are common hormonal reproductive disorders leading to infertility, in which oxidative stress serves a crucial role (6).

Granulosa cells (GCs) are a type of ovarian cell that exist outside oocytes and in follicle walls. Their metabolic activity serves an important role in the quality of the oocyte) (7). GCs are involved in follicular development, oocyte maturation and atresia (7). The role of GCs in the process of follicular differentiation is vital, resulting in optimal conditions for oocyte development, ovulation, fertilization and embryo implantation (7).

Reactive oxygen species (ROS) are oxygen-derived molecules that include superoxide anions, $\mathrm{H}_{2} \mathrm{O}_{2}$ and hydroxyl radicals (8). ROS causes oxidative stress, damage to oocytes and damage to luteinized GCs (9). Increased ROS concentrations in GC reduces the number of retrieved oocytes (10) and in follicular fluid this correlates with poor oocyte and embryo quality (11). SOD is an antioxidant enzyme that acts as a scavenger in oxygen-free radical production, while MDA is 
produced by lipid peroxidation and can be used as a marker of oxidative stress and injury (12). In addition, GSH is a cellular antioxidant that protects cellular proteins from oxidative stress (12).

Salvia miltiorrhiza is a traditional Chinese herbal medicine (13). In Shen Nong's Herbal Classic, the dried roots or rhizomes of Salvia miltiorrhiza Bge are described as a medicine to promote blood circulation and regulate menstruation (14). There are multiple potential biological effects of Salvia miltiorrhiza including antioxidation, anti-inflammation, inhibition of apoptosis and protective effects on organs such as the liver $(15,16)$. Salvia miltiorrhiza solutions are the aqueous extracts of the dried roots or rhizomes of Salvia miltiorrhiza Bge (17). The major chemical components of the water-soluble fractions are salvianic acid A, salvianolic acid B and lithospermic acids (14). The concentrations of salvianic acid A and salvianolic acid B in Salvia miltiorrhiza solution are 2.15 and $1.01 \mathrm{mg} / \mathrm{ml}$ respectively, which have been previously detected by high-performance liquid chromatography-UV (18). Salvia miltiorrhiza solution, as a blood-activating drug, has achieved good clinical results in improving placental circulation in patients with recurrent abortion, as well as improving prognosis in the in vitro fertilization and embryo transfer cycle to treat infertility (19). In addition, previous studies have demonstrated that salvianic acid A and salvianolic acid B attenuated damage induced by oxidative stress $(20,21)$. Treatments with salvianic acid A and salvianolic acid B reduce platelet-derived growth factor-induced ROS formation in rat hepatic stellate cells, possibly via the inhibition of nicotinamide adenine dinucleotide phosphate oxidase and are also effective against hepatic fibrosis in thioacetamide-intoxicated rats in vivo (22). Salvianic acids prevent acute doxorubicin cardiotoxicity in mice via the suppression of oxidative stress (23). Furthermore, mixed aqueous extracts of Salvia miltiorrhiza inhibit hypertension via the inhibition of vascular remodeling and oxidative stress in spontaneously hypertensive rats (20). However, to the best of our knowledge, the effect of salvianic acid A and salvianolic acid B on ovarian granulose cells has not been previously reported. Therefore, the aims of the present study were to investigate the protective effect of Salvia miltiorrhiza solution and its active compounds in $\mathrm{H}_{2} \mathrm{O}_{2}$-induced cell damage of the human ovarian granulosa tumor cells (KGN), and to identify the associated underlying mechanisms.

\section{Materials and methods}

Cell culture and treatment. KGN cells (cat. no. bncc37610; Beijing Beina Chuanglian Biotechnology Research Institute) were cultured in RPMI-1640 medium (Beijing Solarbio Science \& Technology Co., Ltd.) supplemented with 10\% FBS (Gibco; Thermo Fisher Scientific, Inc.) and antibiotics (100 IU/ml penicillin G; 100 mg/ml streptomycin; Beijing Solarbio Science \& Technology Co., Ltd.) in a humidified incubator at $37^{\circ} \mathrm{C}$ with $5 \% \mathrm{CO}_{2}$. The $\mathrm{H}_{2} \mathrm{O}_{2}$ group consisted of KGN cells grown to $80 \%$ confluence, which were then treated with $200 \mu \mathrm{M} \mathrm{H}_{2} \mathrm{O}_{2}$ for $24 \mathrm{~h}$ at room temperature. The treatment group consisted of KGN cells grown to $80 \%$ confluence that were pretreated with Salvia miltiorrhiza solution (0.2, 1 and 5\%), salvianic acid A (3, 10 and $30 \mu \mathrm{M}$; Beijing SLF Chemical Research Institute) and salvianolic acid B (3, 10 and $30 \mu \mathrm{M}$; Nanjing Spring and Autumn Biological Engineering Co., Ltd.) for $4 \mathrm{~h}$ at $37^{\circ} \mathrm{C}$, followed by treatment with $200 \mu \mathrm{M} \mathrm{H}_{2} \mathrm{O}_{2}$ for $24 \mathrm{~h}$ at $37^{\circ} \mathrm{C}$ (24). Salvia miltiorrhiza solution $(1.5 \mathrm{~g} / \mathrm{ml})$ was purchased from Shineway Pharmaceutical Co., Ltd. (cat. no. Z13020777). Stock solutions of Salvia miltiorrhiza solution (0.2, 1 and 5\%), salvianic acid A and salvianolic acid B (3, 10 and $30 \mu \mathrm{M})$ were dissolved in $0.1 \%$ DMSO and stored at $-40^{\circ} \mathrm{C}$. All solutions were freshly prepared from stock solutions prior to each experiment and the final concentration of DMSO was $<0.1 \%$.

Cell Counting Kit-8 (CCK-8) assay. A CCK-8 assay kit (cat. no. EP328-500t; Beijing Zoman Biotechnology Co., Ltd.) was used to investigate the viability of KGN cells. The CCK-8 assay was performed according to the manufacturer's instructions. KGN cells were cultured in 96-well plates at a density of 5,000 cells/well. When grown to $80 \%$ confluence, cells were treated with drugs for $24 \mathrm{~h}$ at $37^{\circ} \mathrm{C}$. Cells treated with $0.1 \%$ DMSO served as the control group. Then, $10 \mu \mathrm{l} \mathrm{CCK}-8$ solution was added to each well for $2 \mathrm{~h}$ at $37^{\circ} \mathrm{C}$. Absorbance was measured at $450 \mathrm{~nm}$ using a microplate reader. Cell viability was expressed as the percentage of the drug group to the control group (100\%). Data represents the mean of three independent experiments.

Malondialdehyde (MDA), superoxide dismutase (SOD), glutathione (GSH) and tumor necrosis factor- $\alpha(T N F-\alpha)$ analysis. Following Salvia miltiorrhiza solution, salvianic acid A and salvianolic acid B treatment, KGN cells were collected and expressions of MDA and GSH were detected, along with SOD activity. MDA concentration was measured using a lipid peroxidation MDA assay kit (cat. no. A003-1; Nanjing Jiancheng Bio-Engineering Institute Co., Ltd.) and SOD activity was measured with a SOD assay kit (cat. no. A001-3; Nanjing Jiancheng Bio-Engineering Institute Co., Ltd.). GSH concentration was measured with a GSH assay kit (cat. no. A006-2; Nanjing Jiancheng Bio-Engineering Institute Co., Ltd.). The cell culture supernatant was obtained by centrifugation at 326.5 $\mathrm{x}$ g. TNF- $\alpha$ concentration in the cell culture supernatant was measured with a TNF- $\alpha$ ELISA kit (cat. no. ARG80120; Arigo Biolaboratories), according to the manufacturer's protocol.

Western blot analysis. Following cell treatment as described above, KGN cells were harvested and cells were lysed using cell lysis buffer RIPA (cat. no. 89900; Thermo Fisher Scientific, Inc.). Total protein concentration was quantified using a Pierce bicinchoninic acid protein assay kit (cat. no. 23227; Thermo Fisher Scientific, Inc). A total of $90 \mu \mathrm{g}$ protein was used for analysis. Protein electrophoresis was performed using $12 \%$ SDS-PAGE and a PVDF membrane that was blocked by $5 \%$ non-fat milk at room temperature for $1 \mathrm{~h}$. Western blotting was used to detect the protein expression of cleaved caspase-3 and cleaved caspase-9 in KGN cells. Primary antibodies included: Anti-cleaved-caspase-3 (1:1,000; cat. no. 9664; Cell Signaling Technology, Inc.), anti-cleaved-caspase-9 polyclonal (1:1,000; cat. no. A2636; ABclonal Biotech Co., Ltd.) and anti- $\beta$-actin monoclonal (1:10,000; cat. no. AC026; ABclonal Biotech Co., Ltd.). The secondary antibodies used were goat anti-rabbit immunoglobulin G-horseradish peroxidase (1:5,000; cat. no. 5220-0336; Kirkegaard \& Perry Laboratories; 
A<smiles>O=C(O)C(O)Cc1ccc(O)c(O)c1</smiles>

Salvianolic acid A
B

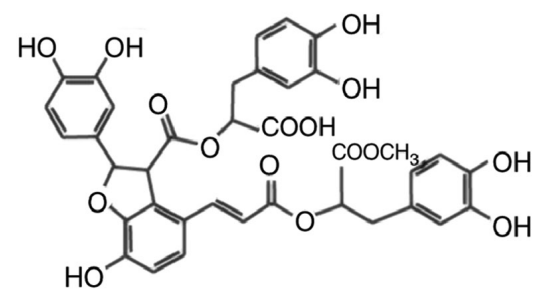

Salvianolic acid B

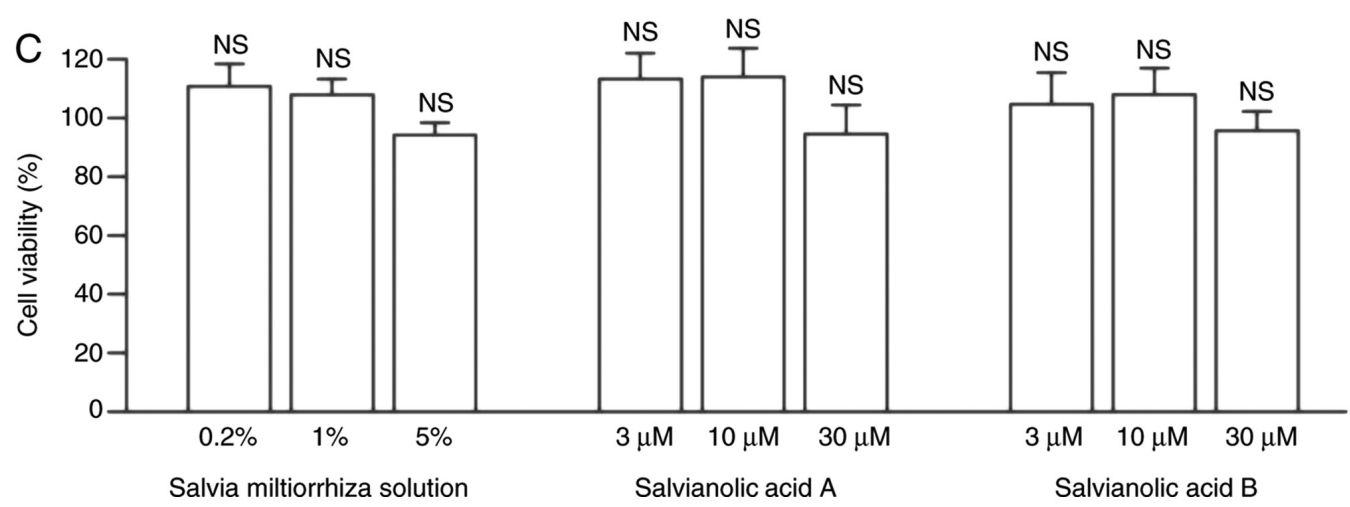

Figure 1. Effects of Salvia miltiorrhiza solution and its active compounds on cell viability in KGN cells. (A) Chemical structure of salvianic acid A. (B) Chemical structure of salvianolic acid B. (C) KGN cells were seeded in 96-well plates and treated with Salvia miltiorrhiza solution (0.2, 1 and 5\%), salvianic acid A or salvianolic acid B $(3,10$ and $30 \mu \mathrm{M})$ for $24 \mathrm{~h}$. Data are presented as the mean \pm SEM of three independent experiments. The viability of untreated cells was set to $100 \%$. NS vs. control group. NS, not significant; KGN, human ovarian granulosa tumor cell line.

Seracare). Protein bands were developed using an EZ-ECL kit (cat. no. 20-500-120; Biological Industries) and analyzed with a Tanon 2500 chemiluminescence imaging system (Tanon Science and Technology Co., Ltd.).

Immunocytochemistry. KGN cells were seeded in 96-well plates at a density of $5 \times 10^{3}$ cells/well on glass coverslips in a 24-multiwell plate. Drug treatment was administered $15 \mathrm{~h}$ after cells were seeded. The cellular detection and localization of TNF- $\alpha$ (TNF- $\alpha$ rabbit polyclonal antibody; cat. no. bs-2081R; BIOSS; 1:100) was determined using an immunocytochemistry assay. Cells were fixed in $4 \%$ paraformaldehyde overnight at $4^{\circ} \mathrm{C}$. Fixed cells were then washed three times with PBS and subsequently incubated with $0.3 \%$ triton at room temperature for $10 \mathrm{~min}$. Samples were then blocked with $10 \%$ goat serum (cat. no. 04-009-1 A; Biological Industries) for $1 \mathrm{~h}$ at room temperature and incubated with primary antibody against TNF- $\alpha$ overnight at $4^{\circ} \mathrm{C}$. Cells were washed three times with PBS and incubated with secondary antibody (goat anti rabbit/mouse horseradish peroxidase kit; cat. no. SP-9000; ZSGB BIO) for $1 \mathrm{~h}$ at $37^{\circ} \mathrm{C}$. After washing three times with PBS, slides were incubated with 3,3'-diaminobenzidine tetrahydrochloride (Beijing Zhongshan Jinqiao Biotechnology Co., Ltd.) for $1 \mathrm{~min}$ at room temperature and immediately washed with water after color development. Slides were then counter-stained with $0.2 \%$ hematoxylin for $5 \mathrm{~min}$ at room temperature. Slides were mounted with $1 \%$ hydrochloric acid Alcohol and then observed under a light microscope, at 400x magnification.

Statistical analysis. Data were analyzed using Origin 9.1 software (OriginLab Corp.) and presented as the mean \pm SEM. Each $n$ value represented data from one culture well. Unless otherwise indicated, $n=8-12$ culture wells were used for each group in each experiment, with repetitions conducted using $\geq 3$ independent dissections for each experiment. Statistical analyses were performed using one-way ANOVA followed by Bonferroni's post hoc test. $\mathrm{P}<0.05$ was considered to indicate a statistically significant difference.

\section{Results}

Effects of Salvia miltiorrhiza solution and its active compounds on the viability of KGN cells. In Shen Nong's Herbal Classic, the dried roots or rhizomes of Salvia miltiorrhiza Bge are described as a medicine to promote blood circulation and regulate menstruation (14). Salvianic acid A (Fig. 1A) and salvianolic acid B (Fig. 1B) are the main water-soluble compounds in Salvia miltiorrhiza solution (18).

The present study investigated the effects of Salvia miltiorrhiza solution and its active compounds, salvianic acid A and salvianolic acid B, on the viability of KGN cells by performing a CCK-8 assay (Fig. 1C). KGN cells were treated with Salvia miltiorrhiza solution or its main active compounds for $24 \mathrm{~h}$. As presented in Fig. 1C, neither Salvia miltiorrhiza solution (0.2, 1 and 5\%), salvianic acid A or salvianolic acid B $(3,10$ and $30 \mu \mathrm{M})$ affected the viability of KGN cells when compared with the control group (100\%; Fig. 1C). Therefore, the present results indicated that Salvia miltiorrhiza solution, salvianic acid A and salvianolic acid B exerted no toxic effects on granulosa cells.

Salvia miltiorrhiza solution, salvianic acid $A$ and salvianolic acid $\mathrm{B}$ suppress $\mathrm{H}_{2} \mathrm{O}_{2}$-induced oxidative stress in $\mathrm{KGN}$ cells. Compared with the control group, the expression of MDA was increased 1.92-fold in the $\mathrm{H}_{2} \mathrm{O}_{2}$-treated group $(\mathrm{P}<0.05$ vs. control 


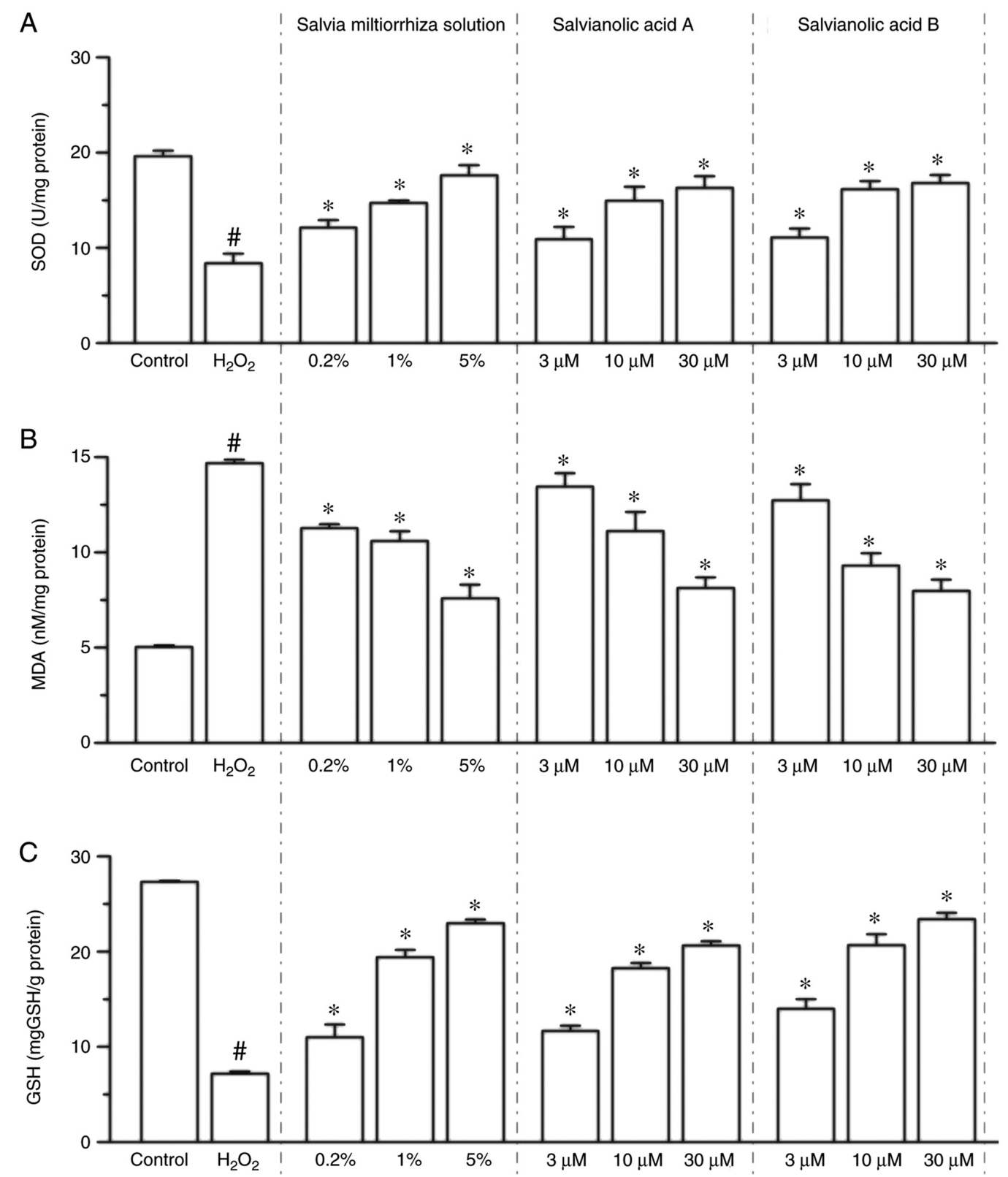

Figure 2. Effects of Salvia miltiorrhiza solution, salvianic acid A and salvianolic acid B on SOD, MDA and GSH in KGN cells. (A) SOD activity, (B) MDA concentration and (C) GSH activity were measured in KGN cells. Data are presented as the mean \pm SEM of three independent experiments. ${ }^{~} \mathrm{P}<0.05$ vs. control group, ${ }^{\mathrm{P}}<0.05$ vs. $\mathrm{H}_{2} \mathrm{O}_{2}$ group. SOD, superoxide dismutase; MDA, malondialdehyde; $\mathrm{GSH}$, glutathione.

group; Fig. 2B), while Salvia miltiorrhiza solution (0.2, 1 and 5\%), salvianic acid A or salvianolic acid $\mathrm{B}(3,10$ and $30 \mu \mathrm{M})$ treatment significantly inhibited the $\mathrm{H}_{2} \mathrm{O}_{2}$-induced increase of MDA levels in a dose-dependent manner $(\mathrm{P}<0.05$; Fig. 2B). It was also revealed that $200 \mu \mathrm{M} \mathrm{H}_{2} \mathrm{O}_{2}$ treatment significantly decreased SOD activity by $57.4 \%$ ( $\mathrm{P}<0.05$ vs. control group; Fig. $2 \mathrm{~A}$ ), while Salvia miltiorrhiza solution (0.2, 1 and 5\%), salvianic acid A and salvianolic acid B (3, 10 and $30 \mu \mathrm{M})$ significantly attenuated the suppression of SOD activity compared with the $\mathrm{H}_{2} \mathrm{O}_{2}$ group $(\mathrm{P}<0.05$; Fig. 2A). In addition, GSH activities were significantly decreased in the $\mathrm{H}_{2} \mathrm{O}_{2}$-treated group ( $\mathrm{P}<0.05$ vs. control group; Fig. 2C), while Salvia miltiorrhiza solution, salvianic acid A and salvianolic acid B significantly attenuated the suppression of GSH activity compared with the $\mathrm{H}_{2} \mathrm{O}_{2}$ group ( $\mathrm{P}<0.05$; Fig. $\left.2 \mathrm{C}\right)$. Collectively, the present results indicated that Salvia miltiorrhiza solution, as well as salvianic acid A and salvianolic acid B, possess antioxidant properties and increase the resistance of KGN cells to oxidation.

Salvia miltiorrhiza solution, salvianic acid A and salvianolic acid $\mathrm{B}$ suppresses $\mathrm{H}_{2} \mathrm{O}_{2}$-induced cleaved caspase-3 and -9 protein expression in KGN cells. Western blotting data demonstrated that treatment with $200 \mu \mathrm{M} \mathrm{H}_{2} \mathrm{O}_{2}$ significantly increased the protein expression of cleaved caspase- 3 by 0.97 -fold and cleaved caspase- 9 by 0.85 -fold compared with the control group $(\mathrm{P}<0.05$; Fig. 3). Treatment with Salvia miltiorrhiza solution significantly attenuated the increased expression of cleaved caspase- 3 and cleaved caspase- 9 compared with the $\mathrm{H}_{2} \mathrm{O}_{2}$ group $(\mathrm{P}<0.05$; Fig. 3A-C). In addition, salvianic acid $\mathrm{A}$ (Fig. 3D-F) and salvianolic acid B (Fig. 3G-I) significantly reversed the increased expression of cleaved caspase- 3 and cleaved caspase- 9 induced by $\mathrm{H}_{2} \mathrm{O}_{2}$. 
A
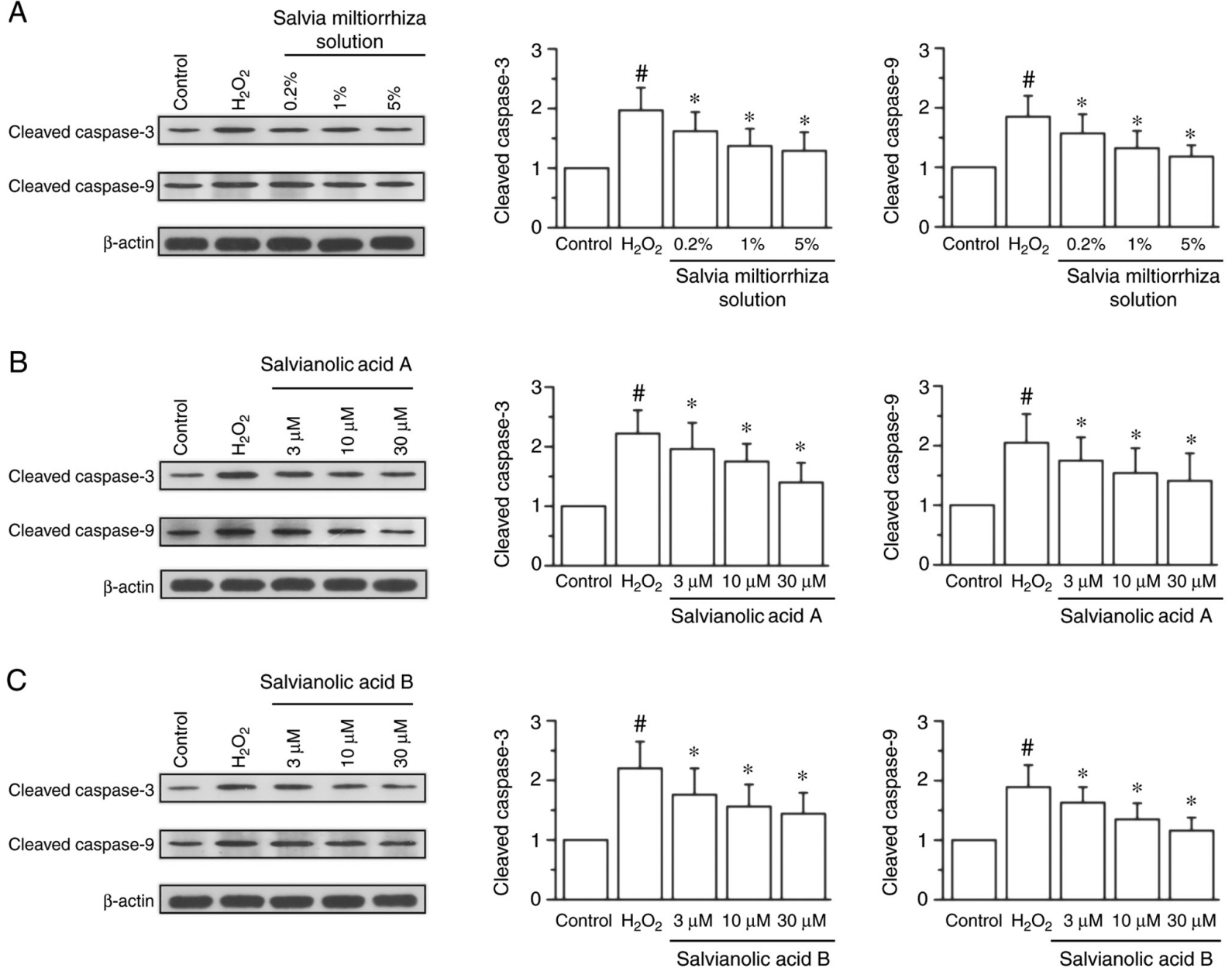

Figure 3. Effect of Salvia miltiorrhiza solution, salvianic acid A and salvianolic acid B on cleaved caspase-3 and cleaved caspase-9 protein expression in KGN cells. Protein expression of cleaved caspase- 3 and cleaved caspase- 9 were analyzed via western blotting after treatment with (A) Salvia miltiorrhiza solution, (B) salvianolic acid A and (C) salvianolic acid B. Data are presented as the mean \pm SEM of three independent experiments. ${ }^{\#} \mathrm{P}<0.05$ vs. control group, ${ }^{*} \mathrm{P}<0.05$ vs. $\mathrm{H}_{2} \mathrm{O}_{2}$ group.

Salvia miltiorrhiza solution, salvianic acid $A$ and salvianolic acid $\mathrm{B}$ suppresses the $\mathrm{H}_{2} \mathrm{O}_{2}$-induced increased expression of $T N F-\alpha$ in KGN cells. To investigate whether Salvia miltiorrhiza inhibits the increased protein expression of $\mathrm{H}_{2} \mathrm{O}_{2}$-induced TNF- $\alpha$, KGN cells were pretreated with Salvia miltiorrhiza solution or its main active compounds for $4 \mathrm{~h}$, followed by the addition of $200 \mu \mathrm{M} \mathrm{H}_{2} \mathrm{O}_{2}$ for $24 \mathrm{~h}$. As presented in Fig. 4B, treatment with $200 \mu \mathrm{M}$ of $\mathrm{H}_{2} \mathrm{O}_{2}$ significantly enhanced the protein expression of TNF- $\alpha$ in KGN cells compared with the control group (Fig. 4A). It was also revealed that Salvia miltiorrhiza solution, in a concentration-dependent manner, significantly decreased the $\mathrm{H}_{2} \mathrm{O}_{2}$-induced upregulation of TNF- $\alpha$ (Fig. 4C). Furthermore, salvianic acid $\mathrm{A}$ and salvianolic acid $\mathrm{B}$ significantly attenuated TNF- $\alpha$ protein upregulation compared with the $\mathrm{H}_{2} \mathrm{O}_{2}$ group (Fig. 4D and E). The present study also investigated the release of TNF- $\alpha$, and demonstrated that Salvia miltiorrhiza solution, salvianic acid A and salvianolic acid $\mathrm{B}$ significantly attenuated TNF- $\alpha$ release induced by $\mathrm{H}_{2} \mathrm{O}_{2}$ (Fig. 4F).

\section{Discussion}

The present results indicated that the survival of granulosa cells was not affected by different concentrations of Salvia miltiorrhiza solution and its main water-soluble compounds. In addition, it was revealed that these compounds exerted no toxic effects on granulosa cells and significantly attenuated the $\mathrm{H}_{2} \mathrm{O}_{2}$-induced increase of MDA levels and $\mathrm{H}_{2} \mathrm{O}_{2}$-induced decrease of SOD and GSH activity. These compounds also reduced the $\mathrm{H}_{2} \mathrm{O}_{2}$-induced increased expression of cleaved caspase- 3 , cleaved caspase- 9 and TNF- $\alpha$. Therefore, the present results indicated that Salvia miltiorrhiza solution and its main water-soluble compounds ameliorated KGN cell damage induced by $\mathrm{H}_{2} \mathrm{O}_{2}$, suggesting that these may protect against oxidative stress in the granulosa cells around oocytes. Thus, Salvia miltiorrhiza may facilitate the treatment of infertility.

Oxidative stress has been implicated in many reproductive disorders including endometriosis, polycystic ovarian syndrome, infertility and aging (25). The degradation of oocyte quality caused by oxidative stress injury is the key factor leading to infertility and adverse fertility outcomes (26). ROS serves an important role in the induction of meiosis in the oocyte and high levels of ROS have been revealed to impair oocyte maturation (27). A previous study indicated that oocyte quality may be affected by an increase in ROS, which was associated with advancing maternal age (25). The clearance 
A

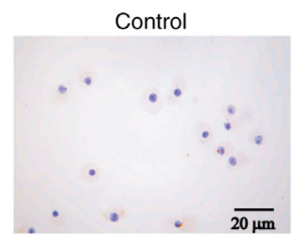

B

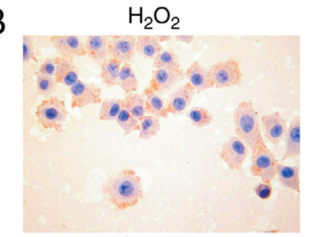

C

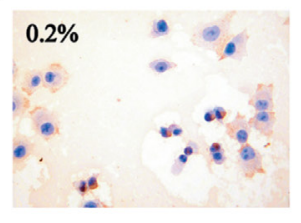

D

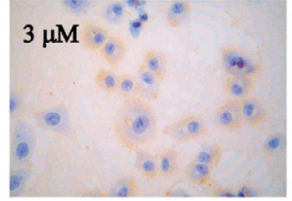

E

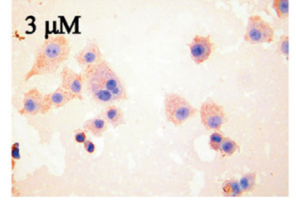

Salvia miltiorrhiza solution

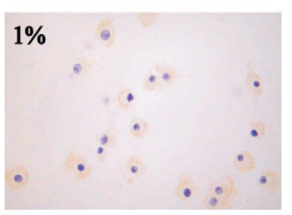

Salvianolic acid A

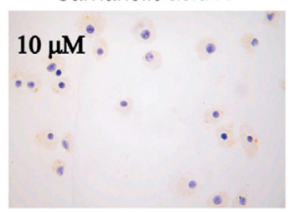

Salvianolic acid B
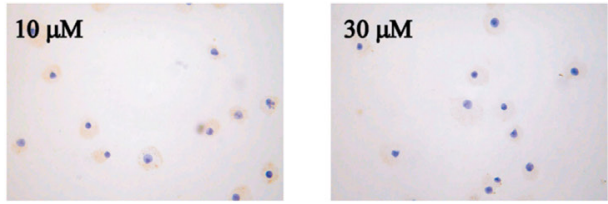

$\mathrm{F}$

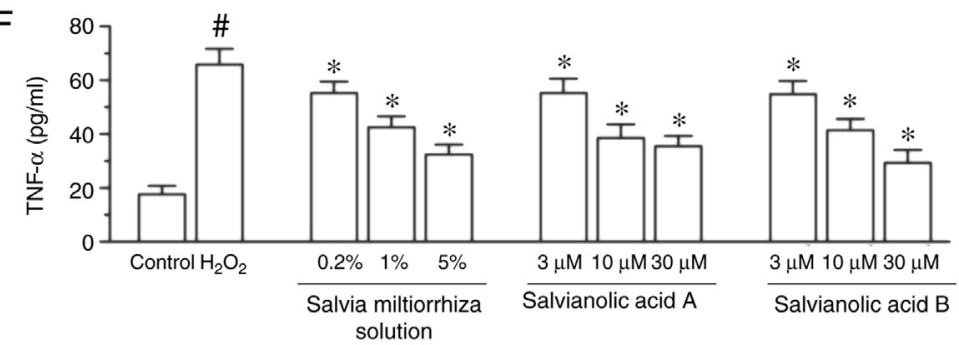

Figure 4. Effect of Salvia miltiorrhiza solution, salvianic acid A and salvianolic acid B on TNF- $\alpha$ protein expression in KGN cells. Representative microscopic photographs were obtained in the (A) control group, (B) $200 \mu \mathrm{M} \mathrm{H}_{2} \mathrm{O}_{2}$ group, (C) Salvia miltiorrhiza solution (0.2, 1 and 5\%) group, (D) salvianic acid A (3, 10 and $30 \mu \mathrm{M}$ ) group and (E) salvianolic acid B group (3, 10 and $30 \mu \mathrm{M}$ ). Magnification, x400. (F) Quantification of TNF- $\alpha$ release measured via ELISA. ${ }^{\#} \mathrm{P}<0.05$ vs. control group and ${ }^{*} \mathrm{P}<0.05$ vs. $\mathrm{H}_{2} \mathrm{O}_{2}$ group. TNF- $\alpha$, tumor necrosis factor- $\alpha$.

of oxidative stress products from follicular fluid is decreased in older women (25). In addition, glutathione, transferase and catalase in ovarian follicular fluid are significantly decreased in older women undergoing in vitro fertilization (25). Therefore, oxidative stress induces granulosa cell discordant function and influences oocyte quality (28).

The antioxidant effect of Salvia miltiorrhiza has been extensively studied. Salvianic acid A reduces liver fibrosis by regulating the caspase-3/cleaved caspase-3 signaling pathway (29). Salvianolic acid B promotes anticonvulsant and anti-apoptotic effects in a pentylenetetrazole-induced seizure model by activitating the AKT/cAMP response element-binding protein/brain-derived neurotrophic factor signaling pathways, including the inhibition of cleaved caspase-3 overexpression (30). Furthermore, TNF serves a crucial role in the amplification of luteolytic signals, mediating vascular regression, and promoting apoptosis and necroptosis of luteal cells (31). Furthermore, it has been demonstrated that salvianolic acid B inhibited TNF- $\alpha$ to extenuate cholestatic liver injury in vivo and in vitro, indicating that the anticholestatic effects of salvianolic acid B may be associated with the inhibition of inflammation and the maintenance of bile acid homeostasis (32). These previous studies indicate that salvianic acid A and B serve an important role in the progression of oxidative stress and apoptosis via caspase and TNF- $\alpha$ (33). However, the molecular mechanism underlying the anti-oxidative effects of Salvia miltiorrhiza in KGN cells is not fully understood. In the present study, Salvia miltiorrhiza solution, salvianic acid A and salvianolic acid B significantly attenuated the $\mathrm{H}_{2} \mathrm{O}_{2}$-induced increase of MDA levels, and the $\mathrm{H}_{2} \mathrm{O}_{2}$-induced suppression of SOD and GSH activities in KGN cells. These compounds also attenuated the increased expression of cleaved caspase-3, cleaved caspase- 9 and TNF- $\alpha$. However, further research is required to investigate the effects of Salvia miltiorrhiza on ovary function using in vivo studies, such as the effects on theca cells, angiogenesis and ovarian 
functions. Furthermore, the effects of Salvia miltiorrhiza on the follicular microenvironment, the endometrium in infertility and the regulation of the pelvic microenvironment require further investigation.

Salvia miltiorrhiza solution and its main water-soluble compounds, salvianic acid $\mathrm{A}$ and salvianolic acid B, may ameliorate oxidative stress damage in $\mathrm{H}_{2} \mathrm{O}_{2}$-induced $\mathrm{KGN}$ cells by suppressing the overexpression of cleaved caspase-3, cleaved caspase-9 and TNF- $\alpha$. Thus, Salvia miltiorrhiza may facilitate the treatment of infertility.

\section{Acknowledgements}

The current study was supported by the Research Foundation of Administration of Traditional Chinese Medicine of Hebei Province (grant no. 2016111).

\section{Funding}

No funding was received.

\section{Availability of data and materials}

The datasets used and/or analyzed during the current study are available from the corresponding author on reasonable request.

\section{Authors' contributions}

YL designed the experiments and performed western blot experiments. YL drafted the manuscript. LK performed oxidative stress experiments. LK and ZQ collected the data. ZQ and XG performed cell culture and CCK-8 experiments. HQ performed cell culture and revised the final manuscript critically for important intellectual content. HL designed the experiments and performed ELISA experiments. All authors read and approved the final manuscript.

\section{Ethics approval and consent to participate}

Not applicable.

\section{Patient consent for publication}

Not applicable.

\section{Competing interests}

The authors declare that they have no competing interests.

\section{References}

1. Mu Z, Sa Y, Sun Z and Yi Y: Ovulation induction with high progesterone levels may be more suitable for elderly patients with low ovarian response. J Gynecol Obstet Hum Reprod: Dec 3, 2019 (Epub ahead of print).

2. Benaglia L, Somigliana E, Santi G, Scarduelli C, Ragni G and Fedele L: IVF and endometriosis-related symptom progression: Insights from a prospective study. Hum Reprod 26: 2368-2372, 2011.

3. Jin B, Niu Z, Xu B, Chen Q and Zhang A: Comparison of clinical outcomes among dual ovarian stimulation, mild stimulation and luteal phase stimulation protocols in women with poor ovarian response. Gynecol Endocrinol 34: 694-697, 2018
4. Nasiri N, Moini A, Eftekhari-Yazdi P, Karimian L, Salman-Yazdi R, Zolfaghari Z and Arabipoor A: Abdominal obesity can induce both systemic and follicular fluid oxidative stress independent from polycystic ovary syndrome. Eur J Obstet Gynecol Reprod Biol 184: 112-116, 2015.

5. Karuputhula NB, Chattopadhyay R, Chakravarty B and Chaudhury K: Oxidative status in granulosa cells of infertile women undergoing IVF. Syst Biol Reprod Med 59: 91-98, 2013.

6. Visioli F and Hagen TM: Antioxidants to enhance fertility: Role of eNOS and potential benefits. Pharmacol Res 64: 431-437, 2011.

7. Attaran M, Pasqualotto E, Falcone T, Goldberg JM, Miller KF, Agarwal A and Sharma RK: The effect of follicular fluid reactive oxygen species on the outcome of in vitro fertilization. Int J Fertil Womens Med 45: 314-320, 2000.

8. Combelles CM, Gupta S and Agarwal A: Could oxidative stress influence the in-vitro maturation of oocytes? Reprod Biomed Online 18: 864-880, 2009.

9. Luderer U: Ovarian toxicity from reactive oxygen species. Vitam Horm 94: 99-127, 2014.

10. Lai Q, Xiang W, Li Q, Zhang H, Li Y, Zhu G, Xiong C and Jin L: Oxidative stress in granulosa cells contributes to poor oocyte quality and IVF-ET outcomes in women with polycystic ovary syndrome. Front Med 12: 518-524, 2018.

11. Liang Y, Tian QH, Mu YX and Du HL: Effects of Cangfu Congxian Decoction on oxidative stress in polycystic ovary syndrome patients.Zhongguo Zhong Xi Yi Jie He Za Zhi 36: 685-689, 2016 (In Chinese).

12. Zhao Y, Kong GY, Pei WM, Zhou B, Zhang QQ and Pan BB: Dexmedetomidine alleviates hepatic injury via the inhibition of oxidative stress and activation of the Nrf2/HO-1 signaling pathway. Eur Cytokine Netw 30: 88-97, 2019.

13. Chen HY, Lin YH, Wu JC, Chen YC, Yang SH, Chen JL and Chen TJ: Prescription patterns of Chinese herbal products for menopausal syndrome: Analysis of a nationwide prescription database. J Ethnopharmacol 137: 1261-1266, 2011.

14. Zhang JP, Zhang YY, Zhang Y, Gao YG, Ma JJ, Wang N, Wang JY, Xie Y, Zhang FH and Chu L: Salvia miltiorrhiza (Danshen) injection ameliorates iron overload-induced cardiac damage in mice. Planta Med 79: 744-752, 2013.

15. Liu J, Yang CF, Lee BL, Shen HM, Ang SG and Ong CN: Effect of Salvia miltiorrhiza on aflatoxin B1-induced oxidative stress in cultured rat hepatocytes. Free Radic Res 31: 559-568, 1999.

16. Tian LL, Wang XJ, Sun YN, Li CR, Xing YL, Zhao HB, Duan M, Zhou Z and Wang SQ: Salvianolic acid B, an antioxidant from Salvia miltiorrhiza, prevents 6-hydroxydopamine induced apoptosis in SH-SY5Y cells. Int J Biochem Cell Biol 40: 409-422, 2008.

17. Lu P, Xing Y, Xue Z, Ma Z, Zhang B, Peng H, Zhou QT, Liu H, Liu Z and Li J: Pharmacokinetics of salvianolic acid B, rosmarinic acid And Danshensu in rat after pulmonary administration of Salvia miltiorrhiza polyphenolic acid solution. Biomed Chromatogr 33: e4561, 2019.

18. Gao Y, Zhang K, Zhu F, Wu Z, Chu X, Zhang X, Zhang Y, Zhang J and Chu L: Salvia miltiorrhiza (Danshen) inhibits L-type calcium current and attenuates calcium transient and contractility in rat ventricular myocytes. J Ethnopharmacol 158 (Pt A): 397-403, 2014.

19. Yao DN, Chen WY and Xiao Y: Exploration into rules of combined Chinese and Western medical treatment on immune infertility. Zhongguo Zhong Xi Yi Jie He Za Zhi 30: 317-319, 333, 2010 (In Chinese).

20. Zhang J, An SJ, Fu JQ, Liu P, Shao TM, Li M, Li X, Jiao Z and Chai XQ: Mixed aqueous extract of Salvia miltiorrhiza reduces blood pressure through inhibition of vascular remodelling and oxidative stress in spontaneously hypertensive rats. Cell Physiol Biochem 40: 347-360, 2016

21. Yang X, Yao W, Li Q, Liu H, Shi H, Gao Y and Xu L: Mechanism of Tang Luo Ning effect on attenuating of oxidative stress in sciatic nerve of STZ-induced diabetic rats. J Ethnopharmacol 174: 1-10, 2015.

22. Tsai MK, Lin YL and Huang YT: Effects of salvianolic acids on oxidative stress and hepatic fibrosis in rats. Toxicol Appl Pharmacol 242: 155-164, 2010.

23. Jiang B, Zhang L, Li M, Wu W, Yang M, Wang J and Guo DA: Salvianolic acids prevent acute doxorubicin cardiotoxicity in mice through suppression of oxidative stress. Food Chem Toxicol 46: 1510-1515, 2008 .

24. Cunha MP, Lieberknecht V, Ramos-Hryb AB, Olescowicz G, Ludka FK, Tasca CI, Gabilan NH and Rodrigues AL: Creatine affords protection against glutamate-induced nitrosative and oxidative stress. Neurochem Int 95: 4-14, 2016. 
25. Carbone MC, Tatone C, Delle Monache S, Marci R, Caserta D, Colonna R and Amicarelli F: Antioxidant enzymatic defences in human follicular fluid: Characterization and age-dependent changes. Mol Hum Reprod 9: 639-643, 2003.

26. Štšepetova J, Baranova J, Simm J, Parm Ü, Rööp T, Sokmann S, Korrovits P, Jaagura M, Rosenstein K, Salumets A, et al: The complex microbiome from native semen to embryo culture environment in human in vitro fertilization procedure. Reprod Biol Endocrinol 18: 3, 2020.

27. Behrman HR, Kodaman PH, Preston SL and Gao S: Oxidative stress and the ovary. J Soc Gynecol Investig 8 (1 Suppl Proceedings): S40-S42, 2001.

28. Tripathi A, Pandey V, Sahu AN, Singh A and Dubey PK: Di-(2-ethylhexyl) phthalate (DEHP) inhibits steroidogenesis and induces mitochondria-ROS mediated apoptosis in rat ovarian granulosa cells. Toxicol Res (Camb) 8: 381-394, 2019.

29. Wang R, Song F, Li S, Wu B, Gu Y and Yuan Y: Salvianolic acid $\mathrm{A}$ attenuates $\mathrm{CCl} 4$-induced liver fibrosis by regulating the PI3K/AKT/mTOR, Bcl-2/Bax and caspase-3/cleaved caspase-3 signaling pathways. Drug Des Devel Ther 13: 1889-1900, 2019.

30. Yu X, Guan Q, Wang Y, Shen H, Zhai L, Lu X and Jin Y: Anticonvulsant and anti-apoptosis effects of salvianolic acid B on pentylenetetrazole-kindled rats via AKT/CREB/BDNF signaling. Epilepsy Res 154: 90-96, 2019.
31. Galvão AM, Szóstek AZ, Skarzynski DJ and Ferreira-Dias GM: Role of tumor necrosis factor- $\alpha$, interferon- $\gamma$ and Fas-ligand on in vitro nitric oxide activity in the corpus luteum. Cytokine 64: $18-21,2013$

32. Li S, Wang R, Wu B, Wang Y, Song F, Gu Y and Yuan Y: Salvianolic acid B protects against ANIT-induced cholestatic liver injury through regulating bile acid transporters and enzymes, and NF- $\kappa \mathrm{B} / \mathrm{I} \kappa \mathrm{B}$ and MAPK pathways. Naunyn Schmiedebergs Arch Pharmacol 392: 1169-1180, 2019.

33. Katary MA, Abdelsayed R, Alhashim A, Abdelhasib M and Elmarakby AA: Salvianolic acid B slows the progression of breast cancer cell growth via enhancement of apoptosis and reduction of oxidative stress, inflammation, and angiogenesis. Int J Mol Sci 20: E5653, 2019.

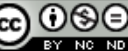

This work is licensed under a Creative Commons Attribution-NonCommercial-NoDerivatives 4.0 International (CC BY-NC-ND 4.0) License. 